\title{
The culture of cancer and the therapeutic impact of qualitative research interviews
}

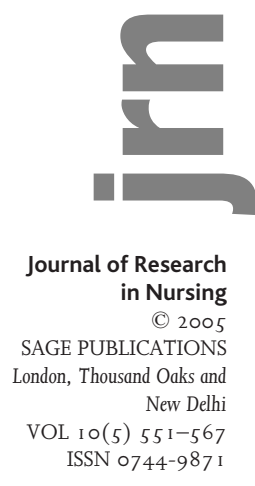

Linda Colbourne MSc, RN

Cancer Research UK Nursing Research Training Fellow

School of Nursing and Midwifery, University of Southampton

Magi Sque PhD, BSc(Hons)Nursing Studies, RN, DipNEd, RNT, ILTM Senior Lecturer

School of Nursing and Midwifery, University of Southampton

\begin{abstract}
This paper is an account of the potential therapeutic impact of research interviews encountered while conducting a qualitative research study. Similarities between the therapeutic (or psychoanalytic) interview and the qualitative research interview are discussed and explored, with examples drawn from a current study. It is suggested that, as a listener, the nurse researcher may offer the participant a mechanism for reflection, greater self-awareness, finding a voice, obtaining information, and venting repressed emotions. Within the context of cancer the participant might have multiple care and information needs to which he/she may expect a therapeutic interaction from a nurse researcher. The potential therapeutic component of the nurse researcher role in the context of cancer care is described and considered. The paper suggests that there may be positive and negative aspects of a therapeutic component to the researcher role and that the researcher should think carefully concerning the stance that he/she will take in the field.
\end{abstract}

Keywords therapeutic interviews, research interviews, context of cancer, human interaction

\section{Introduction}

This paper is an account of how, while conducting a study as a nurse researcher, I [LC] was introduced to, experienced and explored the potential therapeutic impact of qualitative research interviews. The aim of my research was to investigate and explain the experience of men during and 
Journal of Research in Nursing I o(5)

after receiving potentially curative treatment for testicular or prostate cancer, and the corresponding experience of their spouse/partner. The study design was a qualitative, longitudinal, case study, incorporating two recruitment arms, prospective and retrospective. In total twelve couples were recruited to the prospective arm and each participant was interviewed on five separate occasions during and after treatment. The content of this paper relates primarily to the experience of interviewing these couples.

During the initial stages of this study I was influenced by Kvale's ( I 996) work describing the similarity of the impact of therapeutic interviews (or psychoanalytic interviews) and qualitative research interviews. In therapeutic interviews the emphasis is on helping personal change, whereas the aim of qualitative research interviews is not to change the participant but to gain an understanding of his/her experience. Kvale ( I 996) suggests that the main purpose of the therapeutic interview is to alleviate the client's suffering. Gaining increased knowledge of the human situation is an informative and beneficial side-effect of the process. The more I reflected on the data that I had obtained from my study I had to concede that although the aim of my work was not to change or ease suffering, subtle changes in the participant/researcher relationship were evident. The need to explore the concept of the therapeutic impact of the qualitative interview then became important.

The paper provides an overview of the pilot undertaken for the study, at which time I realised that the research interview might offer a therapeutic component. (The pilot study was a mechanism to determine the degree of therapeutic impact.) A description follows of the characteristics of the therapeutic interview, and instances where the qualitative research interview might be described as being therapeutic. The final section considers issues relating to the therapeutic aspect of qualitative interviews within the context of a cancer diagnosis. Where possible, examples from the current study are used to illustrate specific points or arguments.

Table I provides details of participant recruitment criteria and interview time-points for the study.

\section{The pilot study}

The pilot for this study provided more than a review of the suitability of method and relevance of interview schedule; it set the pattern for the character of the research relationship and the level of expected human interaction for the main study. During the pilot interviews I was surprised by the degree of involvement that developed between participant and researcher.

As a result of initial introductions and details contained in the study information sheets, participants were aware of my nursing, and to a 
Colbourne and Sque Qualitative interviews and theapeutic impact

Table 1 Participant recruitment criteria and interview time-points

\begin{tabular}{|c|c|}
\hline Prospective arm participants & Retrospective arm participants \\
\hline $\begin{array}{l}\text { - Patient with a confirmed diagnosis of } \\
\text { prostate or testicular cancer }\end{array}$ & $\begin{array}{l}\text { - Patient met criteria of prospective arm at } \\
\text { diagnosis }\end{array}$ \\
\hline $\begin{array}{l}\text { - Primary surgery completed (biopsy or } \\
\text { orchidectomy) }\end{array}$ & - Two to four years post-treatment \\
\hline $\begin{array}{l}\text { - To start hormone therapy and } \\
\text { radiotherapy or chemotherapy }\end{array}$ & - No evidence of cancer recurrence \\
\hline $\begin{array}{l}\text { - } 18 \text { to } 45 \text { years of age (testicular); } \\
46 \text { years of age or over (prostate) }\end{array}$ & $\begin{array}{l}\text { - Cohabiting with spouse/partner who } \\
\text { experienced treatment phase with patient }\end{array}$ \\
\hline \multicolumn{2}{|l|}{ - cohabiting with a spouse/partner } \\
\hline $\begin{array}{l}\text { Pilot study recruitment target: } \\
2 \text { couples }\end{array}$ & $\begin{array}{l}\text { Pilot study recruitment target: } \\
2 \text { couples }\end{array}$ \\
\hline $\begin{array}{l}\text { Main study recruitment target: } \\
10 \text { couples }\end{array}$ & $\begin{array}{l}\text { Main study recruitment target: } \\
10 \text { couples }\end{array}$ \\
\hline $\begin{array}{l}\text { Interview time-points: pre-oncology } \\
\text { treatment, mid-oncology treatment, } \\
3,9 \text { and } 12 \text { months post-treatment }\end{array}$ & $\begin{array}{l}\text { Interview time-point: One } \\
\text { interview two to four years } \\
\text { post-treatment }\end{array}$ \\
\hline
\end{tabular}

degree, my oncology background. Consequently after interviews had been undertaken with participants, particularly during the staging and treatment phase, they asked questions of me to clarify the logic of treatment decisions, and to gain understanding of the potential impact of treatment in the weeks to come. Although I suggested other avenues for help it was obvious to the participants that I had the knowledge and experience to answer some of their questions. To deny this could have withdrawn trust and contributed to a shallow exchange. Outside the 'formal' part of the audiotaped interview there were wider discussions of life experiences that were not always related to the cancer experience or our roles of participant or researcher. These occasions were when personal moments and thoughts were shared.

As the serial interviews progressed into the post-treatment phase it was evident that there were certain aspects of their experience that participants wanted to resolve. For some reason these issues were often not raised in follow-up consultations. When probing the reason for these omissions, participants often indicated that these were 'little' or 'inconsequential' issues. The priority of follow-up appointments was seen as a mechanism for 'cancer absence monitoring'. Unresolved thoughts and issues included:

- Ambiguity relating to fertility status

- The need to know if contraception was still necessary

- Discrimination in obtaining a mortgage or life insurance 
Journal of Research in Nursing I O (5)

- The future format of follow-up and what would happen after five years of monitoring.

On occasions during or post-interview, participants seemed to engage me in a form of personal 'brainstorming' in an attempt to make sense of the 'little' issues or to develop a plan of action to resolve them.

As a result of the experience I gained during the pilot, and by the time I progressed to the main study there had been a shift in my expectations and approach, and a therapeutic component was not denied or withheld. Thus human interaction that might be regarded as therapeutic was considered and used to inform the data. My changed expectations may have had an effect on my relationship with the study participants, the resultant data and analysis, and I had, therefore, to take this into account.

The issues I have identified so far highlight further questions in relation to the therapeutic component of the qualitative research interview: did participants agree, in part, to become involved in the research study in order to access an additional mechanism of support, information, or advice? Where qualitative research is undertaken by a health professional should an assumption be made that participants will expect (or be entitled to) therapeutic human interaction from the researcher? If the answer to these questions is 'yes', should this have a bearing on who should undertake this form of research? Perhaps some consideration should be given to the extent of the knowledge, experience and skills that are required of the health professional researcher to identify and deal with these situations or at least the availability of a mechanism of referral to other agencies to resolve participant issues.

The pilot study suggested that a relationship had developed, perhaps unconsciously, which involved giving and taking by both parties, which could be equated at times to a therapeutic interaction. The following two sections consider the characteristics of the therapeutic interview and their relevance (or not) to the qualitative research interview.

\section{Characteristics of the therapeutic interview}

Kvale ( I 996) details seven characteristics of the psychoanalytic interview based on Freud's ( I 963) writing:

- It builds up a case study of an individual: Intensive therapy may have taken place over several years

- An open mode of interviewing is used: The content of the exchange is free and non-directive, restricted by the dedicated appointment time

- Interpretations of meanings of incidents are explored: Multiple layers of meaning in a dream or a symptom are explored, for example, with the possibility of continual reinterpretation as therapy proceeds 
Colbourne and Sque Qualitative interviews and theapeutic impact

- A temporal dimension is taken: All facets of an experience are examined

- Human interaction is involved: There is reciprocal involvement of patient and therapist

- An investigation of pathology is undertaken: This includes investigation of abnormal behaviour, symptoms and dreams

- Instigation of change is attempted: This is as a means of changing patient self-understanding and action.

Two of these characteristics seem particularly relevant to the research interview: the taking of a 'temporal dimension' and 'human interaction'. These are considered in more depth below.

\section{The temporal dimension}

By taking a temporal dimension, a therapeutic interview entwines aspects of past, present and future. According to Kvale (I 996): 'The remembrance of the past is an active force of therapeutic change, and therapy aims at overcoming the repressions of the past as well as the present resistance against making the unconscious conscious' (Kvale, I 996).

Although the qualitative research interview does not advocate therapeutic intervention, elements of the past temporal dimension may be evident. Participants in my study were discussing, sharing, and exploring their past, present and future experiences of an emotive time in their lives. All of the study participants commented to some degree that they did not actively attempt to repress or deny their cancer experience but that they tended to distance it, push it to the past, forget, or romanticise the episode. For example, post-treatment descriptions of the therapy experience were less vivid than those given during the time of treatment, and chunks of the experience were omitted when they were recounting specific events of the therapy phase. The following two quotes from Ian (during post-treatment interviews at three and nine months respectively) reveal aspects of repression:

'... I don't know if you suppress it or forget; I don't think you forget, but I don't know what the right word is; you almost romanticise the whole thing ... you don't sort of quite remember the pain, the anguish, and the 'manicness' that you felt and everything that you went through, 'cos at the time it was really horrific; but I look back on it now, I don't know, it's a bit odd'.

‘. . I don't think you ever get normal, to your prior life. I don't think you'll ever get back to that, and that's why I say I think you need to sort of box that off, and sort of effectively start over again ....

Other participants expressed comments similar to those of Ian i.e. that is, that the cancer experience had to be dealt with in some way - to be 'boxed off' mentally — before moving on to a post-treatment existence. 
Journal of Research in Nursing I o(5)

One of my initial concerns when beginning interviewing for this study was that I might cause emotional harm asking participants to re-live what could be considered an unpleasant time of their lives. Certainly, both therapeutic and non-therapeutic aspects of the research interview were seen during the study. Toby revealed himself (at three months posttreatment) as one of those who had a positive response to the interviews:

Toby: I enjoy the interviews; I look forward to the interviews.

Researcher: Do you?

Toby: Yeah, sad that. I am ... I like being able to talk to somebody, out of the loop sort of thing; it's quite good, even if it's nothing to do with getting any worries off my chest or anything; it's just nice to talk to somebody out of the loop, and to be asked questions ... 'cos sometimes you make me think [about the experience], as well which is, you know, is good ....

Toby illustrated that the interview was a time when he could consider aspects of his experience that he might not have put into context without rehearsing these issues to someone not emotionally involved; that is, to someone outside the family and health professional group. This type of admission seems to align to some degree with Kvale's ( I 996) description of making the unconscious, conscious.

After conducting the last interview with each couple, they were sent a thank you letter and a comment reply slip and offered the opportunity to comment on the study process. These responses frequently identified that re-evaluating the cancer experience during the interview could be beneficial. The following excerpt from a reply slip from Adam and Faith illustrates this:

'We both feel that this is a very beneficial part of the healing process and coming to terms with the cancer. Perhaps an interview like this would benefit other cancer patients'.

At the time of his interview Adam was two years and I I months posttreatment, yet there seemed to be issues that both he and his wife wanted to talk through, and this, he felt, was easier to achieve with a 'cancerknowledgeable stranger'. These types of admissions seems to align to some degree with Kvale's ( I 996) description of making the 'unconscious conscious'.

The influence of the unconscious on the conscious may also have had an impact in different and less beneficial ways for participants. For instance, Steve described feeling depressed after the completion of treatment. He was continually trying to force himself to be positive - to count his many blessings: he had a happy, stable relationship with his partner, a good job, financial stability and a second chance of life. However, with the advent of his 'cancer diagnosis anniversary' it appeared that repressed emotions relating to the treatment experience and 
Colbourne and Sque Qualitative interviews and theapeutic impact

multiple fears of the potential of a cancer-related future were beginning to haunt him. These manifested as flashbacks of traumatic instances during chemotherapy administration and the realisation that cancer would always be an element of his future life. Thus he had a fluctuating fear of recurrence and the possibility of infertility and the potential need for assisted conception.

Steve recognised that he was experiencing emotional difficulty and needed to deal with his unconscious becoming conscious in an attempt to resolve future turmoil. However, he said that although his thoughts and experience at the time of interview were not pleasant, talking was useful. A detrimental aspect of this particular interview was that for his convenience the venue chosen was the cancer centre where he had had his treatment. In a further interview, he conceded that this environment had carried with it many negative associations of the cancer experience and had compounded his depressed mood. Consequently, the hospital-based interview with him may, unintentionally, have caused him added trauma.

A further example of repression of thought and therapeutic affect identified from the study were comments from the spouse/partners of the need to talk about the couple's cancer experience so that thoughts and fears could be explored. Some of these women used the research interview to verbalise frustrations and emotions. Four of the men did not want to talk, examine, or think about their experience and this resulted in a repression of emotions between them and their spouse/partner. It might be suggested that this form of repression was a form of coping strategy. However it seemed that the interview provided an opportunity for emotional expression for four of the women. This is illustrated by Susan's comment at the pre-oncology treatment interview:

'We are coping with it so far because he doesn't want to talk about it. I do want to talk about it but he doesn't want to, so I respect his wishes.'

In my study journal I frequently recorded the content of a conversation that had occurred with a spouse/partner once the tape recorder had been turned off and the 'official' part of the interview had ended. Susan said that she did want to talk about the couple's cancer experience and in particular her own feelings, and frequently did so after the taped interview. Susan explained that she resented the impact that the cancer might have on her life, particularly if her husband relapsed and she was forced to become a full-time carer. Susan felt guilty at having and expressing these thoughts because she was not the one with the cancer diagnosis or the person having to endure treatment. She commented that health professional input should be directed towards her husband and not towards herself and that the interview provided a legitimate avenue for her own self-awareness and expression. 
Journal of Research in Nursing I o(5)

The experience of the participants in my study has indicated that a prospective, longitudinal, qualitative interview research design offers an opportunity for emotional consciousness to be revealed, especially as the researcher/participant relationship develops, and the therapeutic aspect of the process may assist greater self-awareness and understanding. Thurschwell (2000) describes the unconscious as the 'wastepaper basket of the mind' where, in the right circumstances, it can be brought to the conscious. Maybe the research interview can be the vehicle through which the researcher (and perhaps participant) is able to retrieve and learn.

Revelation of repressed thoughts or the unconscious is one of the characteristics of the psychoanalytic interview. The following section explores the characteristics of human interaction that appear to have relevance to the research interview.

\section{Human interaction as therapy}

According to Kvale (I996:76), who identified human interaction as a characteristic of the psychoanalytic interview, '...therapy takes place through an emotional human interaction with a reciprocal personal involvement.' Although this relationship appears to be deliberately manipulated in the therapeutic interview in order to bring about client change, it cannot be denied that, while longitudinal research is being undertaken, a relationship evolves between participant and researcher that may involve empathy, caring, respect, reciprocal sharing and disclosure. In qualitative research it is expected that the researcher will explore the impact of this relationship on each party and on the research.

In my study, evidence of human interaction developed in several ways. Particular examples were the sharing of distressing and emotional experiences, expressions of joy and celebration at the birth of a participant's grandchild, and of a couple's engagement. Offers of practical help, and the giving of 'thank-you' tokens were another indication of human interaction. One participant was very open concerning his reasons for his involvement in the study: he hoped, through his involvement in the study, to be able to help others in the future and saw me as a means of being able to give him the information he needed or to explain how to access the hospital system. In this case I needed to make clear the boundary of our relationship at the outset, and I made clear that my mechanism of facilitation would be to direct him to an appropriate health professional or agency who could offer him help.

Interaction between researcher and participant is not always so immediate, however. One participant in the study - Julien — was very forthright in his manner and went through the motions of welcome, but I often came away from interviews feeling that I had done something 
wrong, or that, intellectually, I was his inferior. I found solace, however, in the descriptions by Cartwright and Limandri ( I 997) of researcher roles and participant relationships. They illustrated that at the start of a research relationship the roles of participant and researcher are generally that of 'stranger-stranger' and that it takes time for the development of self-disclosure and to foster trust to create a 'friend-friend' relationship or, at a minimum, a 'researcher-participant' one. However, there seemed to be little progression from the 'stranger-stranger' relationship with Julien. During my fifth encounter with him — at the three month post-treatment interview - an opportunity arose for me to ask him what he thought about the study research process, following which he outlined several factors that had caused him to be so frustrated and angry. He revealed that what he had found most distressing was the means by which he had been asked to give his consent to take part in the research, which had been to ask permission to continue with the study even in the event of a relationship breakdown between the couple. This was a stipulation at the time of gaining ethics approval, but Julien had taken great exception to this request and after his explanation I totally understood why. He commented:

'Actually I can say it now, I actually resented you asking. I didn't want to think about us splitting up or something, but that was a lot to do with my mental state at the time ...I felt there was an intimation that we could split over it ... and I actually felt quite angry. Don't get me wrong; what came out of it was that there was no malice [on your part], and there was no hidden agenda'.

Julian explained that, at the time of diagnosis, his relationship with his wife was the only solid foundation he had to cling to, and the idea that the cancer experience might destroy this sanctuary had never entered his mind until I had highlighted it. I had questioned something that was too painful to contemplate at this time of crisis in this man's life. We then talked through this, and other points, with greater understanding on both sides, and the relationship became easier. I learnt from this encounter and appreciated that at least we had reached the point where honest feelings could be expressed. However, it had taken time, an instance of open sharing, and an evolving research relationship before meaningful human interaction and learning could occur.

\section{Does 'human interaction' equate to therapy?}

Does the 'human interaction' that is experienced in qualitative research interviewing equate to the therapy of a therapeutic interview? Kvale ( 1 996) has highlighted it as an important characteristic, and Hutchinson et al. ( I 994) suggest that human interaction can provide a positive, therapeutic component to the research interview. Hutchinson et al. ( I 994) also 
Journal of Research in Nursing I O (5)

comment that, although the risks of the qualitative research interview are widely discussed, positive outcomes, such as the therapeutic impact of this type of interview, are given less attention.

As a consequence of their experience of conducting qualitative research interviews Lipson ( I 984), Hutchinson et al. ( I 994), Kvale ( I 996), Aylott (2002) and Ahlberg and Gibson (2003) identify the potential outcomes of human interaction: catharsis, altruism, self-acknowledgement, sense of purpose, self-awareness, empowerment, healing.

In a dialogue cited between eight academic researchers (Morse, I 994), the potential for therapy to be a by-product of the qualitative research interview was discussed. From this discussion Morse ( I 994) considers that 'therapeutic-ness' evolves from participants being offered the opportunity of a listener, which gives them an opportunity to self-reflect, the result being greater self-awareness. During this dialogue the other academics identified that 'therapeutic-ness' may be gained cathartically as a result of participants telling their story, or finding a voice. The consensus from this group was that the qualitative interview is frequently therapeutic for the participant, but they identify this as 'serendipitous therapy', an apt observation in that it removes it from the intent of therapy that is part of the psychoanalytic interview.

Data from my study uphold the views expressed in Morse's ( I 994) publication in that all participants demonstrated a wish to tell their story in the hope that this would inform care and help others. This need to 'find a voice' was poignantly illustrated by one of the partners. During several interviews with this woman came a tirade of perceived care oversights and frustrations with the healthcare system. Thoughts about complaining on completion of treatment had been contemplated, but her realisation that long-term follow-up would be required made her fearful of some form of reprisal if complaints were made. This participant in particular used the research interview, in part, to find an anonymised voice.

Being aware of the potential for human interaction in the qualitative research interview environment can assist in the understanding of a particular participant/researcher relationship. However, Kvale (I 999) cautions that during longitudinal studies where problems can be highlighted, the researcher's ability to listen may be interpreted as a 'quasitherapeutic relationship'. This is dangerous territory for the researcher, who may not have the knowledge or skills to deal with this responsibility. A referral option or mechanism for dealing with this scenario should be considered by the researcher in advance of undertaking any interviews. 


\section{The cancer interview: Context and therapeutic effect}

I was reminded continually during the course of my study that a qualitative research interview is not undertaken in a vacuum. Context and the individual impact of researcher and participant(s) are undeniable aspects, together with the potential for human interaction and exchange that are therapeutic. However, a further line of questioning for this study may be to consider the culture of cancer and the fear that this disease engenders. Sontag (I99I) has written extensively on the metaphors of illness and specifically those allied to tuberculosis, AIDS, and cancer. Sontag's (I 99 I) main stance is that socially created negative metaphors applied to diseases such as cancer cause nothing but fear and dread.

All of the participants in the study described cancer as a life-threatening illness and used particular adjectives to describe it in their narrative, such as 'evil', 'invading', 'nasty', 'dirty'. Also, discussions on the issue of mortality were common, as were negative associations with specific cancers.

All the male participants in my study had been diagnosed with cancer and subsequently had had treatment. Furthermore, all spouse/partner participants had experienced this life phase with them. The social impact of a 'feared' disease will undoubtedly have some effect on a person, and the following section offers some examples of the impact of this fear and the therapeutic response that the interviewer may bring through human interaction.

\section{Instances of patient fears that may have an effect on the qualitative research interview and its therapeutic component}

The research participant who has cancer may be walking a tightrope of thoughts and emotions. Myths about the condition, prior personal experience and metaphors created and used by society may induce guilt or shame on the part of the participant and restrict or hinder free expression by the participant or the researcher. So how might these fears and experiences have an effect on the qualitative research interview and its potential therapeutic component? In an attempt to answer this question I highlight some instances from my study.

\section{Looking for positives}

Participants frequently sought re-affirmation of data they had been given in relation to their prognosis. This manifested in the need to confirm the estimated percentage of cure given during medical consultations and the likelihood of severity of side-effects with a given treatment modality. 
Journal of Research in Nursing I o(5)

In my study journal I often referred to this as the 'cancer prognostic mantra'. Participants regularly repeated comments such as 'The doctor said I had a 98\% chance of cure' or 'The doctor said this is the best cancer to have' as reinforcement that that they would get through the experience. They also sought positive comparison by comparing their experience with that of other patients, particularly those who were nearing the end of treatment or those who had completed it. In a study exploring the experience of medical surveillance among men with testicular teratoma, Jones and Payne (2000) describe this behaviour as 'searching for safety signals', a mechanism that assists in adjustment to threatening events.

During my study, the interview was frequently used by participants to gain reassurance and confirmation: they needed support for the case for potential cure against the cultural myth that cancer invariably equates to death. Participants appeared to need continual reinforcement that there was hope - that their particular cancer situation was amenable to active intervention.

\section{Asking for information on treatment}

During interviews I was asked questions relating to treatment, sideeffects, post-treatment fertility, the format of treatment and follow-up and how relapse might be identified or prevented. At his nine-month posttreatment interview, Kevin summed up why he asked so many questions: it was because he needed to be 'cancer educated':

'... it's sort of not knowing anything. I think it would be easier if, as I found out about testicular cancer, ... someone [would] come round and tell [you] all the ins and outs, all the pluses and minuses so you'd know what to expect'.

Kevin clarified this statement further by commenting that, although, generally, people fear cancer they do not need to know in detail about different cancers and their treatments; it is only when they are faced with a cancer diagnosis that their lack of knowledge is made apparent.

Because of the speed of the treatment phase and its emotional and physical impact, the opportunities for information-gathering are reduced. Access to a research nurse may therefore be seen as an avenue to rectifying this situation. This perhaps reinforces the need for participants to have one-to-one tailored input from health professionals. It could be that the health professional researcher is in the ideal position to offer timely information as the participant's cancer experience evolves and as questions or information deficits arise.

On occasions I was also seen as an alternative avenue for getting a referral, a means of helping to speed up treatment, or to access results, especially-post treatment. Anxiety also appeared to be related to the possibility 
Colbourne and Sque Qualitative interviews and theapeutic impact

that the cancer would return and that the cancer 'fight' would have to be reinstated. In this instance I seemed to be considered as a means of enabling the individual to return to the acute oncology team if necessary.

\section{Checking the logic of cancer thoughts}

At times I was used as a sounding board from which participants could bounce their thoughts relating to the possible causes of their cancer and the logic of the cancer prevention plans and lifestyles they hoped to follow. There were also questions about the passing on of 'cancer genes' to children - guilt that this might be the case - but also queries as to how to investigate this possibility and deal with the consequences. When a participant believed the cancer diagnosis had been mishandled or ignored, he/she often wanted to talk through his/her assumption that symptom warning signs had been ignored by health professionals and the potential impact on prognosis owing to treatment delay. These encounters seemed to illustrate the need for participants to gain meaning from their experience, a mechanism also identified by Hutchinson et al. (I 994), Kvale ( I 996) and Ahlberg and Gibson (2003). Searching for meaning and understanding in relation to a crisis is a way of attempting to assert control, and is often characterised as a coping mechanism (Taylor, i 983). The interview might be one means used by participants to attempt to adapt to the unknown of their cancer situation.

\section{Hiding cancer or not talking about it}

Sontag ( I 99 I) suggests that western society is unable to accept death and that cancer patients are isolated to some degree because of this attitude. Social isolation can be induced by society or the individual. In my study there were participants who openly discussed their cancer diagnosis, yet $60 \%$ were selective in whom they told. Two men hid their diagnosis and forbade their spouse/partner to discuss the cancer diagnosis beyond the home. In this situation the spouses/partners appeared to use the interview as a therapeutic encounter to talk and off-load their fears and frustrations, and also their guilt at having to withhold the truth from family and friends. Studies by Lipson ( I 984) and Aylott (2002) also found participants experiencing social and/or emotional isolation because of repressing their feelings and thoughts for fear of causing distress to their family and friends. Lipson ( I 984) and Aylott (2002) identified that the qualitative research interview provided participants with an opportunity to talk and that this in turn delivered a therapeutic emotional dimension. 
Journal of Research in Nursing I O(5)

\section{Implications of the qualitative research interview and its potential therapeutic impact}

The above examples indicate the potential for the qualitative research interview to provide elements of therapeutic input. The participants appeared to be trying to make sense of their cancer in the light of their personal biography and experience, social constructions of cancer, and the medical view of their prognosis. The interviews served as a means of sounding out and reaffirming their own, and sometimes new, developing beliefs and knowledge. In some cases these new beliefs were in conflict with the stereotypical negative social and cultural views of cancer. It seemed that at times it was difficult for participants to have faith in their personal experience and potentially good prognostic outcome in the prevailing negative culture of cancer.

The study interviews were undertaken between treatment cycles and health professional consultations. It was during these periods, when safety signals could not be secured from the healthcare teams, that doubt and negative thoughts appeared to arise, so that the interviews offered a timely opportunity for a therapeutic/human interaction.

Participants recruited to this study seemed to have expectations of the qualitative research interview other than the giving of their time and revealing their experience. In some cases this expectation evolved over time; in others (a minority), the interview was used as a means of securing an information source from day one. These expectations may have been raised by my explanation to participants on meeting them that I had a nursing and oncology background. Perhaps it should have been obvious to me that this would mean that participants would expect knowledgeable exchanges and supportive information. I could have hidden my nursing and oncology background from participants but felt that this would have been dishonest and false. Some health professional researchers (Wilde, I 992; Schutz, I 994; Finlay, I 998; Chesney, 200 I; Carolan, 2003) argue that it is impossible to hide such professional knowledge and that it is unproductive to do so. It is indeed difficult for the nurse in the nurse researcher not to surface during a participant/researcher exchange. However, as long as the researcher has given some thought as to how this dilemma will be resolved, and the deliberations recorded as to the possible impact of this on the research, acknowledging one's professional knowledge can be used as a positive outcome of the researcher/participant relationship.

What is important is that the researcher maintains a balanced approach; does not become too much the nurse, overstep the mark or begin to take over care from the healthcare team. To do so would be to tread in dangerous territory, because the researcher may well be out of the health profes- 
sional communication loop so that important facts for the delivery of care bypass him/her. In an area of healthcare such as oncology where emotional and physical effects are common occurrences for patients, a lone researcher could easily get out of his/her depth. It is therefore important that researchers know their limitations.

There are, though, positive aspects of the potential therapeutic impact of the qualitative research interview, the primary one being the opportunity to provide elements of support, care and empathy at an important time for the participant. The interaction may well provide greater understanding of the participant's needs and experience, which could inform care.

Health professional researchers do not need to be trained counsellors; that is not their role. As identified earlier in this paper, some of the participants were at a difficult time in their lives, and found it beneficial to talk to someone anonymous - someone 'out of the loop'. During this study it was found that the researcher needed to be prepared to give time to the participants, and not treat the interview as just a formal data-collecting episode. The researcher should therefore be prepared to give something to participants in return.

A pilot study provides an important opportunity for researchers to find, assess, and understand the supportive/information issues that participants may raise during a study. By taking note of these issues, researchers can prepare themselves for the personal stance needed and for any onward referral patterns that may be required during the main study.

\section{Conclusion}

Although the primary aims are different, there are similarities between the research and the therapeutic interview; both seek to understand, interpret and re-interpret, and often result in self-exploration on the part of the researcher or therapist and participant (Hutchinson and Wilson, I 994; Kvale, I 996). All parties involved in a research interview will be influenced by the process in some way. In particular, a longitudinal study design involving serial interviews provides the potential for researcher/participant interaction and relationship development. The qualitative research interview may provide the opportunity to deliver a therapeutic component to the participant. None of these effects should be ignored or shunned. It may even be beneficial to pre-empt and be prepared for this form of human interaction, and to offer it. Often, access to a researcher is the only opportunity a patient has between treatments to maintain hope, vent fears, or gain information or clarification. The qualitative researcher should consider the potential therapeutic benefits of the research interview and the possibility of enhancing the care experience for participants. 


\section{Key points}

- There are commonalties between the therapeutic (psychoanalytic) interview and the qualitative research interview

- Participants and researcher may expect a form of therapeutic, human interaction as part of the interview process, especially if the research design involves serial interviews

- There needs to be wider debate concerning the therapeutic 'care' the health professional researcher could provide during the research process.

\section{Acknowledgement}

The work is supported by Cancer Research UK [CUK] grant number CI 5 I 5/A I 87 .

\section{References}

Ahlberg, K., Gibson, F. (2003) What is the story telling us? Using patient experiences to improve practice. European Journal of Oncology Nursing 7: I 49-I 50.

Aylott, M. (2002) Interviewing as therapy: Researching parents' experiences of their child's life-threatening illness requiring ECMO. Nursing in Critical Care 7: I 63- 70.

Carolan, M. (2003) Reflexivity: A personal journey during data collection. Nurse Researcher I0: 7-I 4.

Cartwright, J., Limandri, B. ( I 997) The challenge of multiple roles in the qualitative clinician researcher-participant client relationship. Qualitative Health Research 7: $223-235$.

Chesney, M. (200 I) Dilemmas of self in the method. Qualitative Health Research I I : I $27-$ I 35 .

Finlay, L. ( 1998 ) Reflexivity: An essential component for all research? British Journal of Occupational Therapy 6I: 453-456.

Freud, S. ( 1963 ) Therapy and Technique. New York: Collier.

Hutchinson, A., Wilson, H. ( 1 994) Research and the therapeutic interviews:

A poststructuralist perspective. In: Morse, J.M. (ed) Critical Issues in Qualitative Research Methods. London: Sage, pp 300-3 I 5.

Hutchinson, S.A., Wilson, M.E., Wilson, H.S. ( 1994 ) Benefits of participating in research interviews. IMAGE: Journal of Nursing Scholarship 26: I 6 I - I 64.

Jones G.Y., Payne, S. (2000) Searching for safety signals: The experience of medical surveillance amongst men with testicular teratomas. Psycho-Oncology 9: 385-394.

Kvale, S. ( 1996$)$ An Introduction to Qualitative Research Interviewing 3rd Edition. London: Sage.

Kvale, S. ( I 999) The psychoanalytic interview as qualitative research. Qualitative Inquiry 5: 87-I I 3 .

Lipson, J.G. ( I 984) Combining researcher, clinical and personal roles: Enrichment or confusion? Human Organisation 43: 348-352.

Morse, J.M. ( I 994) Critical Issues in Qualitative Research Methods. London: Sage. 
Colbourne and Sque Qualitative interviews and theapeutic impact

Schutz, S.E. ( I 994) Exploring the benefits of a subjective approach in qualitative nursing research. Journal of Advanced Nursing 20: 4 I 2-4 I 7 .

Sontag, S. ( I 99 I) Illness as Metaphor and AIDS and its Metaphors zrd Edition. London: Penguin Books.

Taylor, S.E. ( 1983 ) Adjustment to threatening events: A theory of cognitive adaptation. American Psychologist November i 983: i I 6 I-I I 73.

Thurschwell, P. (2000) Sigmund Freud. London: Routledge.

Wilde, V. ( 1 992) Controversial hypotheses on the relationship between researcher and the informant in qualitative research. Journal of Advanced Nursing I 7: 234-242.

Correspondence should be addressed to:

Linda Colbourne

c/o Research Office, School of Nursing and Midwifery,

Nightingale Building,

University of Southampton,

Highfield,

Southampton SO I 7 i BJ. 